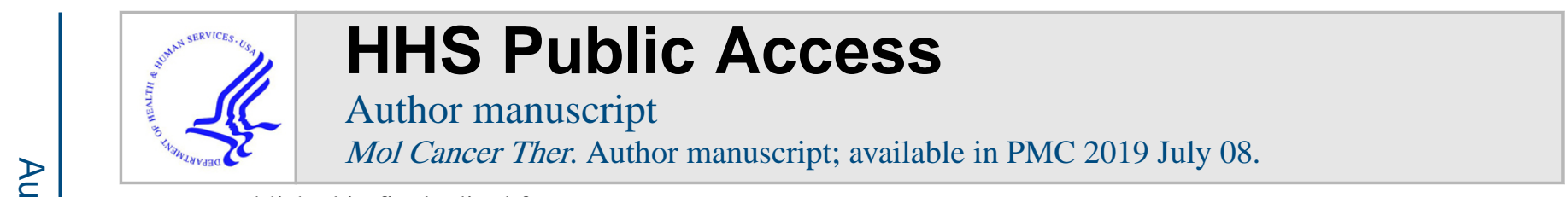

Published in final edited form as:

Mol Cancer Ther. 2019 June ; 18(6): 1181. doi:10.1158/1535-7163.MCT-19-0471.

\title{
Retraction: In Vitro and In Vivo Interactions between the HDAC6 Inhibitor Ricolinostat (ACY1215) and the Irreversible Proteasome Inhibitor Carfilzomib in Non-Hodgkin Lymphoma Cells
}

\author{
Girija Dasmahapatra, Hiral Patel, Johnathan Friedberg, Steven N. Quayle, Simon S. Jones, \\ and Steven Grant
}

This article (1) has been retracted at the request of the editors. The AACR Publications Department was notified that the U.S. Department of Health and Human Services' Office of Research Integrity determined that G. Dasmahapatra, the first author of the above-mentioned article, engaged in research misconduct by falsifying and/or fabricating data that appeared in the 2014 article (2). Specifically, respondent reused, and/or relabeled Western blot panels and mouse images and claimed they represented different controls and/or experimental results in: Fig. 3A (JNK 1 and Tubulin), 3B (JNK and Tubulin), and 3C (Tubulin; ref. 2). The matter was reviewed by members of the AACR Publications staff and the MCT editors, who agree that the figure manipulation present in the article merits retraction.

A copy of this Retraction Notice was sent to the last known email addresses for all 6 of the authors. 3 authors (J. Friedberg, S.S. Jones, and S. Grant) agreed to the retraction; 2 authors (H. Patel and S.N. Quayle) did not respond; and 1 author (G. Dasmahapatra) could not be located.

\section{References}

1. Dasmahapatra G, Patel H, Friedberg J, Quayle SN, Jones SS, Grant S. In Vitro and In Vivo interactions between the HDAC6 inhibitor ricolinostat (ACY1215) and the irreversible proteasome inhibitor carfilzomib in Non-Hodgkin Lymphoma cells. Mol Cancer Ther 2014;13:2886-97. [PubMed: 25239935]

2. Findings of research misconduct. Federal Register 2015;80:76703-4. [PubMed: 27737268] 